\title{
Steering of methanol reforming selectivity by zirconia-copper interaction
}

\author{
Lukas Mayr $^{1}$, Bernhard Klötzer ${ }^{1}$, Dmitry Zemlyanov ${ }^{2}$ and Simon Penner $^{1 *}$ \\ ${ }^{1}$ Institute for Physical Chemistry, University of Innsbruck, Innsbruck \\ ${ }^{2}$ Birck Nanotechnology Center, Purdue University, West Lafayette
}

Keywords: In-situ Photoelectron Spectroscopy, High-resolution Electron-Energy Loss Spectroscopy, Methanol Steam Reforming, Model Catalyst

*Corresponding Author: simon.penner@uibk.ac.at, Tel: 00435125075056, Fax: 00435125072925 


\begin{abstract}
"Inverse" $\left(\mathrm{ZrO}_{2} / \mathrm{ZrO}_{\mathrm{x}} \mathrm{H}_{\mathrm{y}}\right.$ on $\left.\mathrm{Cu}\right)$ and "real" $\left(\mathrm{Cu}\right.$ nanoparticles on $\left.\mathrm{ZrO}_{2}\right)$ ultra-high vacuum/ambient pressure model catalyst studies were performed using methanol steam reforming as test reaction. The catalytic profile was correlated with structural and spectroscopic analysis using X-ray Photoelectron and Auger Electron Spectroscopy and HighResolution Electron-energy Loss Spectroscopy. Access to water activation-dependent pathways is achieved by special $\mathrm{Cu} / \mathrm{ZrO}_{\mathrm{x}} \mathrm{H}_{\mathrm{y}}$ phase boundary or interfacial sites formed during reaction, which were studied with respect to surface coverage, island size and chemical state of $\mathrm{Cu} / \mathrm{Zr}$ metal/oxide species. On the "real" model system, particle size effects increasing the amount of unwanted $\mathrm{CO}$ were observed beyond interfacial selectivity-steering effects. Oxidation of $\mathrm{Zr}^{0}$ to $\mathrm{Zr}^{+4}$ during reaction forms the most efficient phase boundary with respect to redox-active sites. Ability for reversible hydroxylation of $\mathrm{Zr}$ combined with a submonolayer $\mathrm{Zr}$ coverage for maximum $\mathrm{ZrO}_{\mathrm{x}} \mathrm{H}_{\mathrm{y}} / \mathrm{Cu}$ phase boundary dimensions are the most critical parameters in catalyst preparation.
\end{abstract}




\section{Introduction}

Zirconia's mechanical and chemical properties make it a relevant material for several technical and industrial applications. Besides application in chemical sensors (often also in its yttrium-stabilized modification) [1-3], as protective layers, or as gate oxides in the semiconductor industries [4-6], the usage as a catalyst is currently under investigation for several systems. An excellent overview of $\mathrm{ZrO}_{2}$ used as support as well as part of the active site in heterogeneous catalysis is given in ref. [7]. Methane combustion [8], $\mathrm{CO}_{2}$ hydrogenation to methanol [9] and low temperature methane oxidation [10] are examples for reactions catalyzed by $\mathrm{ZrO}_{2}$-supported active metal particles. Recently, the attention was focused on the catalytic relevance of $\mathrm{ZrO}_{2}$-based cermet-materials [11] and $\mathrm{Zr}$-containing alloys/intermetallic compounds for $\mathrm{C}_{1}$-surface reactions such as methanol steam reforming (MSR) [12] or in natural gas-operated solid oxide fuels cells [13, 14]. The latter are constructed using yttrium-stabilized zirconia as electrolyte material and therefore have enhanced thermal compatibility with catalytically active Zr-based electrodes to avoid thermal damage by different expansion coefficients. For this application numerous other materials such as Ni-based anode composites show catalytic activity and selectivity in SOFCs [15] and also progress is made regarding the coking issue and the unwanted formation of carbonnanotubes. However, innovative $\mathrm{Cu}$-based systems [16-18] have the potential for even better catalytic properties for fuel activation while suffering less from carbon-induced deactivation. In particular, with respect to MSR, meaningful $\mathrm{Cu}-\mathrm{Zr}$ UHV model catalyst studies are missing so far, mostly because of the difficulties in preparing ultrathin $\mathrm{Zr}, \mathrm{ZrO}_{2}$ and $\mathrm{ZrO}_{\mathrm{x}} \mathrm{H}_{\mathrm{y}}$ films using commercial preparation techniques such as thermal evaporation. This is mainly caused by disadvantageous material properties such as a high melting point in combination with low vapor pressures of both $\mathrm{Zr}^{0}$ and $\mathrm{ZrO}_{2}$. Thermal evaporation of metallic zirconium has been applied by Paulidou et al. [19] based on a design using W as filament and support. To avoid 
W contamination and provide atomically clean layers that are suitable for catalysis experiments we decided to use another technique. The self-developed enhanced sputter technique [20] allows us to prepare ultra clean thin films of $\mathrm{ZrO}_{2}$ or of mixed $\mathrm{ZrO}_{2} / \mathrm{Zr}$ species and therefore to subsequently perform model catalyst studies on $\mathrm{Cu}(\mathrm{ox}) / \mathrm{Zr}(\mathrm{ox})$ systems relevant for $\mathrm{C}_{1}$-surface chemistry. The term $\mathrm{Cu}(\mathrm{ox}) / \mathrm{Zr}(\mathrm{ox})$ is used to express the participation of both species on catalytic redox processes and describes a general oxidation state without referring to a specific one. It includes (partial) hydroxylation, (partial) oxidation, sub-oxides and all oxidation states between metallic and full oxidation (i.e. $+\mathrm{II}$ for $\mathrm{Zr}$ and $+\mathrm{I}$ for $\mathrm{Cu}$ ). To better understand the $>99 \% \mathrm{CO}_{2}$ selectivity described in ref. [12], the methanol steam reforming process has been selected as a model reaction. Purnama et al. synthesized $\mathrm{ZrO}_{2}$ supported nanostructured $\mathrm{Cu}$ by a wet-chemical sol-gel method and subsequent reduction and found this system to be more active, more stable and more $\mathrm{CO}_{2}$ selective than $\mathrm{CuO} / \mathrm{ZnO}$ supported on $\mathrm{Al}_{2} \mathrm{O}_{3}$ [12].

As shown for the $\mathrm{Pd}-\mathrm{Zn}$ [21-23] and $\mathrm{Cu}-\mathrm{Zn}$ system [24], the formation of ultra-thin oxidic overlayers under reaction conditions by oxidative $\mathrm{Zn}$ segregation from a bi-metallic precursor leads to a maximum quantity of active sites for methanol steam reforming. This universal concept is beneficial for two reasons: A maximum of metal-oxide interface is formed due to the statistic distribution of $\mathrm{Zn}$ in the bi-metallic pre-catalyst, and secondly, the surface oxide layer is very thin and therefore electronically influenced by the substrate, resulting in distinct catalytic properties compared to the bulk oxide [22, 24, 25].

Hence, the aim of this study is to show the possibility to replace $\mathrm{Zn}(\mathrm{ox})$ by potentially redox active $\operatorname{Zr}(\mathrm{ox})$ species and to still form active and highly selective sites for steam reforming processes such as MSR by UHV model catalyst synthesis. Due to the outstanding thermochemical properties of zirconia (e.g. the very high melting point), a higher sintering stability of the respective "real" catalysts is likely. This might play an even more important 
role when extending the studies from MSR to the SOFC-relevant methane reforming processes, meeting analogous requirements concerning water activation but needing at the same time significant higher operating temperatures (above $900 \mathrm{~K}$ ) for efficient fuel activation.

Because of their surface sensitivity, XPS, AES, LEIS and HREELS where selected for ex-situ sample analysis and, after thorough pre-catalyst characterization, catalytic experiments were performed in our UHV-compatible recirculation batch reactor. The results clearly show the beneficial interaction between the two species $\mathrm{Cu}$ and $\mathrm{ZrO}_{\mathrm{x}} \mathrm{H}_{\mathrm{y}}$ when they are present in a specific state on the surface with respect to oxidation level of $\mathrm{Zr}$ and surface topography.

\section{Experimental Setup}

\section{$U H V$-chamber and batch reactor}

Sample preparation and characterization was performed in an UHV chamber with attached reaction cell, described in more detail elsewhere [26]. It is pumped by a turbo molecular pump, an ion getter pump and a titanium sublimation pump resulting in a base pressure in the low $10^{-9}$ mbar range. For spectroscopic analysis, the chamber is equipped with a hemispherical electron and ion analyzer (Thermo Fisher Electron Alpha 110), a double anode X-ray gun (Mg/Al, XR 50, Specs) for XPS, an ion gun (Omicron 100) sufficient to produce 1 $\mathrm{kV} \mathrm{He}^{+}$Ions for LEIS and an electron beam gun (KPI EGPS-2017B) for Auger electron spectroscopy. Additionally, a mass spectrometer (Balzers) for residual gas analysis, an electron beam heating unit for sample heating and $\mathrm{an}^{\mathrm{Ar}^{+}}$ion sputter gun for sample cleaning is attached. A three way gas inlet allows to dose $\mathrm{O}_{2}$ (Messer, 5.0), $\mathrm{H}_{2}$ (Messer 5.0) or $\mathrm{O}_{2}$ cleaned Ar (Messer 5.0, Supelpure ${ }^{\circledR}-O$ Oxygen/Moisture trap) via leak valves into the chamber. 
All XPS spectra where recorded with a Mg Ka X-ray source $(\mathrm{h} v=1253.6 \mathrm{eV})$ at $250 \mathrm{~W}$ and the "magic angle" to the analyzer. The rotatable sample holder allows performing manual angle-resolved depth-profiling in the range of $0^{\circ}$ to $90^{\circ}$. For XPS the analyzer was operated using a constant pass energy of $20 \mathrm{eV}$. For Auger electron spectroscopy a constant electron energy of $3 \mathrm{keV}$ was selected.

We evaporated $\mathrm{Cu}$ by a $\mathrm{VG} \mathrm{e}^{-}$-beam micro evaporator using a $0.25 \mathrm{~mm} \mathrm{Cu}$ wire looped around a $1 \mathrm{~mm}$ Ta rod as mechanical stabilizer. The evaporation rate was monitored by a water-cooled quartz crystal microbalance. Moreover, the film thickness was estimated from XPS via an attenuated overlayer model and the surface coverage via an non-attenuated model (described in detail in the supplementary information) to verify the amount of deposited material [27]. The results of these two quantification approaches are well comparable (aberrance $<10 \%)$

The $\mathrm{Zr}$ deposition was performed by an all self-developed and -constructed UHV-compatible mini-sputter-source that is described in detail in ref. [20]. It is mounted on a standard $2.5 \mathrm{in}$. CF flange and allows reproducible deposition of atomically clean (sub-)monolayers of either $\mathrm{ZrO}_{2}$, when operated in $\mathrm{O}_{2}$ (reactive) sputtering mode or $\mathrm{Zr}^{0} / \mathrm{Zr}^{+4} \mathrm{O}_{2}$, with this ratio depending on the UHV and Ar sputter gas quality (amount of $\mathrm{O}$ containing residuals).

For catalytic testing in the ambient pressure cell, a long z-transfer rod allows fast and reliable transfer without exposure to air. The all-quartz-glass high-pressure (up to 1 bar) batch reactor is equipped with a gas chromatograph with either intermediate or continuous EID-MS detection to determine the exact gas composition at any point of reaction. Continuous partial pressure detection is performed via a capillary leak to the GC-MS. The quartz-glass reactor with a total circulation volume of $296 \mathrm{ml}$ was designed to measure small reaction rates and selectivity patterns within a temperature range of room temperature up to $1300 \mathrm{~K}$. A circulation pump ensures a constant flow and gas intermixing and an attached gas-premixing 
unit allows to set arbitrary compositions of the attached gases (methanol, methane, deionized and degassed water, $\mathrm{O}_{2}, \mathrm{H}_{2}$ and $\mathrm{He}$ ). The sample holder itself is entirely made of quartz glass to avoid background reactivity from hot metal parts and is designed for $20 \mathrm{~mm}$ x $18 \mathrm{~mm}$ metal foils [26].

A partial pressure of 8 mbar Argon added to all gas mixtures allows to correct for the thermal expansion due to the temperature increase and the simultaneous gas loss through the capillary for continuous MS detection. For partial pressure calculations, all base-line-corrected-MS signals where calibrated with pure substances with quantitative consideration of fragmentation. For all catalytic experiments shown in this work, the following initial conditions for MSR where applied: 12 mbar Methanol, 24 mbar water, 8 mbar Argon, He; total pressure: 1 bar. After an equilibration time of $10 \mathrm{~min}$, a temperate ramp of $10 \mathrm{~K} \mathrm{~min}^{-1}$ up to $623 \mathrm{~K}$ was set, followed by an isothermal period at $623 \mathrm{~K}$. Note that due to the type of the reaction cell (batch reactor) used, only the total methanol conversion reached at the end of the isothermal reaction period for all experiments is stated. As for a discussion about mass and heat transport limitations, we refer to a thorough discussion of the catalytic setup in ref. [28].

All experiments except for the HREEL spectra were performed using a $20 \mathrm{~mm}$ x $18 \mathrm{~mm}$ foil ultra-clean $\mathrm{Cu}$ foil (99.9999\%, Alfa Aesar) with a thickness of $0.125 \mathrm{~mm}$ for $\mathrm{Cu}$ and 0.127 $\mathrm{mm}$ for Zr. The foils were cleaned before loading to the UHV chamber in a water and an ethanol ultrasonic bath for $20 \mathrm{~min}$, respectively.

\section{High-resolution electron energy loss spectroscopy (HREELS)}

The HREEL spectra as well as the corresponding XPS spectra were recorded in an Omicron Analysis chamber with a base pressure of $5 \times 10^{-11}$ mbar on a LK HREELS 5000 spectrometer. An attached preparation chamber was used for sample cleaning and thin film sputtering. A primary electron energy of $7 \mathrm{eV}$ was used. For HREELS we used a $\mathrm{Cu}(111)$ single crystal 
because of suitable mounting on the sample holder and the better defined surface of a single crystal, resulting in higher intensity and better resolution in the HREEL spectra.

\section{Preparation}

For the "real" model system $\left(\mathrm{Cu}\right.$ on a $\mathrm{ZrO}_{2}$ substrate), the pristine $\mathrm{Zr}$ foil was oxidized in 1 bar $\mathrm{O}_{2}$ and $623 \mathrm{~K}$ in the UHV-attached reactor cell to form a fully surface-covering layer of $\mathrm{ZrO}_{2}$ (thicker than XPS analysis depth). Varying amounts of $\mathrm{Cu}$ were thermally evaporated on top of this $\mathrm{ZrO}_{2}$ layer using a VG mini-evaporator. The evaporation rate was controlled by a quartz microbalance and the theoretical island height calculated from the nominal layer thickness and the $\mathrm{Cu} / \mathrm{ZrO}_{2}$ surface ratio determined by LEIS.

For the "inverse" System $(\mathrm{Zr}(\mathrm{ox})$ on $\mathrm{Cu})$ a $\mathrm{Zr}$ foil was mounted as sputter target to our selfconstructed sputter source [20]. Reactive sputtering occurred already with traces of water or $\mathrm{CO}$ in the background sputter atmosphere (from residual gas molecules, pressure $2 \times 10^{-9}$ mbar). With added $\mathrm{O}_{2}$ fully oxidized $\mathrm{Zr}$ sub-monolayers on bulk $\mathrm{Cu}$ surfaces were produced. Figure 1 shows an angle-resolved XPS depth profile of a uniform $\mathrm{ZrO}_{2}$ layer of $10 \AA$ nominal thickness with a slightly pronounced shoulder towards lower binding energies indicating incomplete oxidation of $\mathrm{Zr}$.

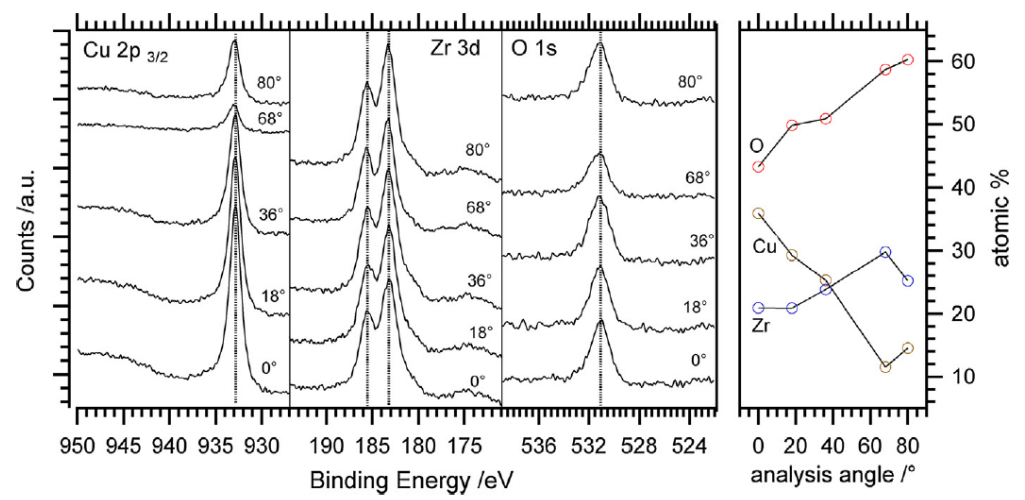

Fig. 1. Angle-resolved XPS of a sputtered $10 \AA \mathrm{Z} \mathrm{ZrO}_{2}$ layer on $\mathrm{Cu}$ ("inverse" model system). Surface sensitivity increases with decreasing photoelectron "take-off" angle. For experimental details see [26]. A shoulder toward lower binding energies in the $\mathrm{Zr} 3 \mathrm{~d}$ region suggests a minor contribution from reduced $\mathrm{Zr}$ species. No major change of the oxidation state with analysis depth is observed, which indicates a constant $\mathrm{Zr}^{+\mathrm{IV}} /$ reduced $\mathrm{Zr}$ ratio within the growing layers during deposition. 
This shoulder is present with similar intensity for all angles, which indicates a constant ratio of $\mathrm{Zr}^{+\mathrm{IV}}$ and a more reduced $\mathrm{Zr}$ species within the growing layer during deposition. For $\mathrm{ZrO}_{2}$ the $\mathrm{Zr} 3 \mathrm{~d}$ peak position was found to be at $182.5-183 \mathrm{eV}$ [29] and the peak position for O $1 \mathrm{~s}$ at $530.9 \mathrm{eV}$ [30]. The purified Argon (described above) was used to operate the sputter source in non-reactive sputtering mode. In addition, any other possible contaminations were minimized (i.e. by extensive degassing of all metal parts that are subject to be heated during sputtering and by removing the passivation $\mathrm{ZrO}_{2}$ layer of the sputter target). By reducing the amount of background gas molecules, the fraction of metallic $\mathrm{Zr}$ could be increased up to a level of about 0.5 (Figure 9). Due to the propensity of $\mathrm{Zr}$ to very quickly react with oxygen and most oxygen containing molecules of the residual gas $\left(\mathrm{CO}, \mathrm{H}_{2} \mathrm{O}\right)$, residual $\mathrm{Zr}^{+\mathrm{IV}}$ species are always present. Since both oxidation states and their interaction with $\mathrm{Cu}$ under MSR conditions were carefully studied, a clear correlation to catalytic results could be established. As described in detail below, the partially metallic pre-catalyst forms hydroxylated $\mathrm{Zr}$ under MSR conditions as determined from HREELS.

\section{Analysis of the XPS Data}

All spectra were analyzed using the CasaXPS software program, version 2.3.16 Pre-rel 1.4 (Casa Software Ltd.) [31]. A Shirley background was applied to all spectra and the associated Scofield relative sensitivity factors were considered for quantification. For peak fitting of the Zr 3d peaks a weighted sum of Gaussian and Lorenzian peak shapes (CasaXPS line shape SGL(30)) was used. A doublet separation ( $\mathrm{Zr} 3 \mathrm{~d}_{5 / 2}$ vs. $\left.\mathrm{Zr} 3 \mathrm{~d}_{3 / 2}\right)$ of $2.4 \mathrm{eV}$ for both metallic $\mathrm{Zr}$ [27] and zirconia [32] was used for fitting. The doublet area was kept constant at 3:2 as arising from spin-orbit d-electron coupling. Electron attenuation lengths were taken from the NIST database SR 82 [33] and the orbital asymmetric parameter from the ELETTRA online database of ref. [34]. The surface coverage was estimated by a non-attenuated overlayer model on a semi-infinite substrate for fractional coverage [35]. For thickness estimations, a 
model that considers photoelectron attenuation through the substrate and the overlayer was used. While the coverage estimation is the more meaningful model for fractional (sub-) monolayers, a multi-monolayer film can be more accurately described by thickness model because of the consideration of the electron attenuation by the overlayer. For low thicknesses, the influence of the attenuation effect is low and therefore the results of both models (coverage in ML and thickness in $\AA$ ) are convertible under consideration of the chemical composition of the overlayer. Details of these calculations are given in the Supplementary Information in Section A.

\section{Results}

\section{1. "Real" model system $\mathrm{Cu}$ on $\mathrm{ZrO}_{2}$}

In this part of the study, we take a closer look on a zirconia substrate layer that is doped with $\mathrm{Cu}$ to determine the activity of new sites formed by $\mathrm{Cu}-\mathrm{ZrO}_{2}$ interaction. We observed a shift in selectivity as a function of $\mathrm{Cu}$-overlayer thickness and particle/island shape because of the formation of special sites for fractional $\mathrm{Cu}$ coverages on $\mathrm{ZrO}_{2}$. The individual product formation pattern turned out to be a function of $\mathrm{Cu}$ particle size, coverage and chemical state. As a direct proof for the existence of such a $\mathrm{Cu}-\mathrm{Zr}$ phase boundary, ion scattering spectra for all prepared catalyst where collected (Figure 2). For the "real" system (upper panel), but also for the "inverse" system (lower panel), $\mathrm{Cu}$ as well as $\mathrm{Zr}$ can clearly be detected. Quantitative results are summarized in Table 1 as well as in Table 2. 


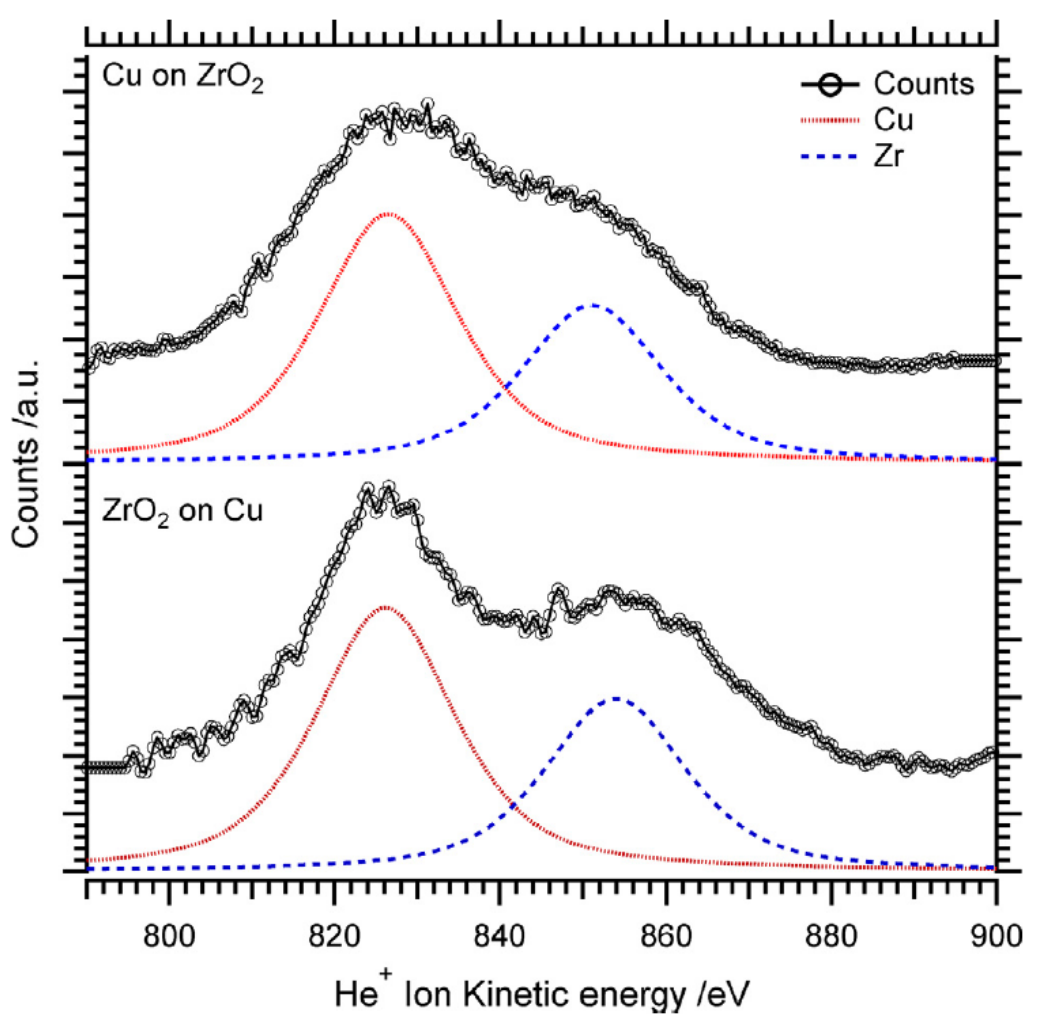

Fig. 2. The $1 \mathrm{keV} \mathrm{He}+$-ion scattering spectra on the two catalyst systems prove the coexistence of both species at the surface. The peak fit shows the deconvolution of the overlapping $\mathrm{Cu}$ and $\mathrm{Zr}$ peaks. Quantitative results for all spectra results are summed up in Table 2. The spectrum for the "inverse" model catalyst was taken on a $5.4 \AA \mathrm{ZrO}_{2}$-covered $\mathrm{Cu}$ foil (from the attenuated XPS overlayer model); the one for the "real" model catalyst sample on a $1.8 \AA \mathrm{Au}$ overlayer on $\mathrm{ZrO}_{2}$.

\section{Ex-situ XPS analysis}

Due to the insulating $\mathrm{ZrO}_{2}$ layer, severe charging effects up to $1.5 \mathrm{eV}$ take place on the "real" model catalyst system. The most essential information about the chemical state can still be extracted, whereas the quantification is not affected at all. Since the shift caused by charging can be estimated from the $\mathrm{Cu} 2 \mathrm{p}$ signal because of its constant $2 \mathrm{p}_{3 / 2}$ binding energy of the main peak for all relevant oxidation states $\left(\mathrm{Cu}^{0}\right.$ and $\left.\mathrm{Cu}^{+}, \mathrm{Cu}^{2+}\right)$ as well as from a correlation of the relative $\mathrm{O} 1 \mathrm{~s}$ and $\mathrm{Zr} 3 \mathrm{~d}$ shifts, a correction can be performed. Figure 3 highlights the BE/KE-corrected XPS spectra and X-ray stimulated-AES of the Cu LMM transition. 


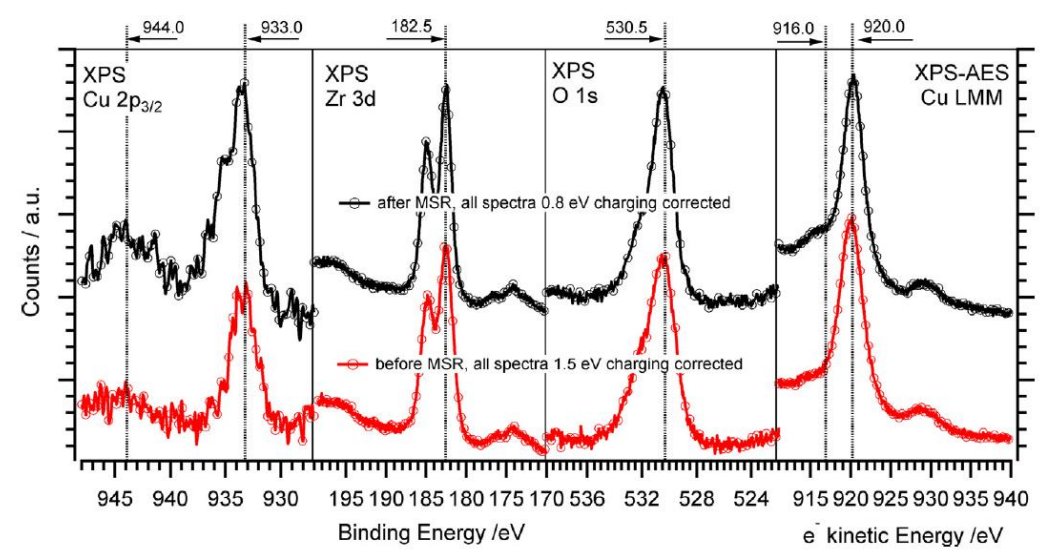

Fig. 3. Charging-corrected XPS and XPS-Auger spectroscopy of the Cu L.MM transition before and after MSR. The appearance of a CuO-associated satellite at $944.0 \mathrm{eV}$, as well as the Auger fingerprint at kinetic energy $916 \mathrm{eV}$, indicates partial formation of $\mathrm{Cu}$ oxides.

The following conclusions can be drawn: (i) the oxidation state for $\mathrm{Zr}$ in all experiments is $+\mathrm{IV}$ before and after MSR reaction, (ii) no significant chemical shift in the $\mathrm{Zr} 3 \mathrm{~d}$ region was detected, (iii) for $\mathrm{Cu}$, the main state is metallic but the AES fingerprints (Figure 3 panel 4) as well as the satellite peak around $944.0 \mathrm{eV}$ after MSR in the $\mathrm{Cu} 2 \mathrm{p}_{3 / 2}$ region (Figure 3, left panel) indicate the partial formation of $\mathrm{Cu}^{2+}$ species due to partial oxidation under reaction conditions. Therefore, not only $\mathrm{Cu}^{0}$ is present, but also (partially) hydroxylated $\mathrm{Cu}^{1+}$ and $\mathrm{Cu}^{2+}$ species are likely. The corresponding Auger spectra also show a peak around $916 \mathrm{eV}$, indicating the presence of $\mathrm{Cu}^{+}$species in addition to $\mathrm{Cu}^{0}$ [36].

\section{Pure $\mathrm{Cu}$ and $\mathrm{ZrO}_{2}$ in $\mathrm{MSR}$}

Figure 4 depicts the corresponding MSR experiments as formation rate vs. time curves during a heating and a subsequent isothermal period. 


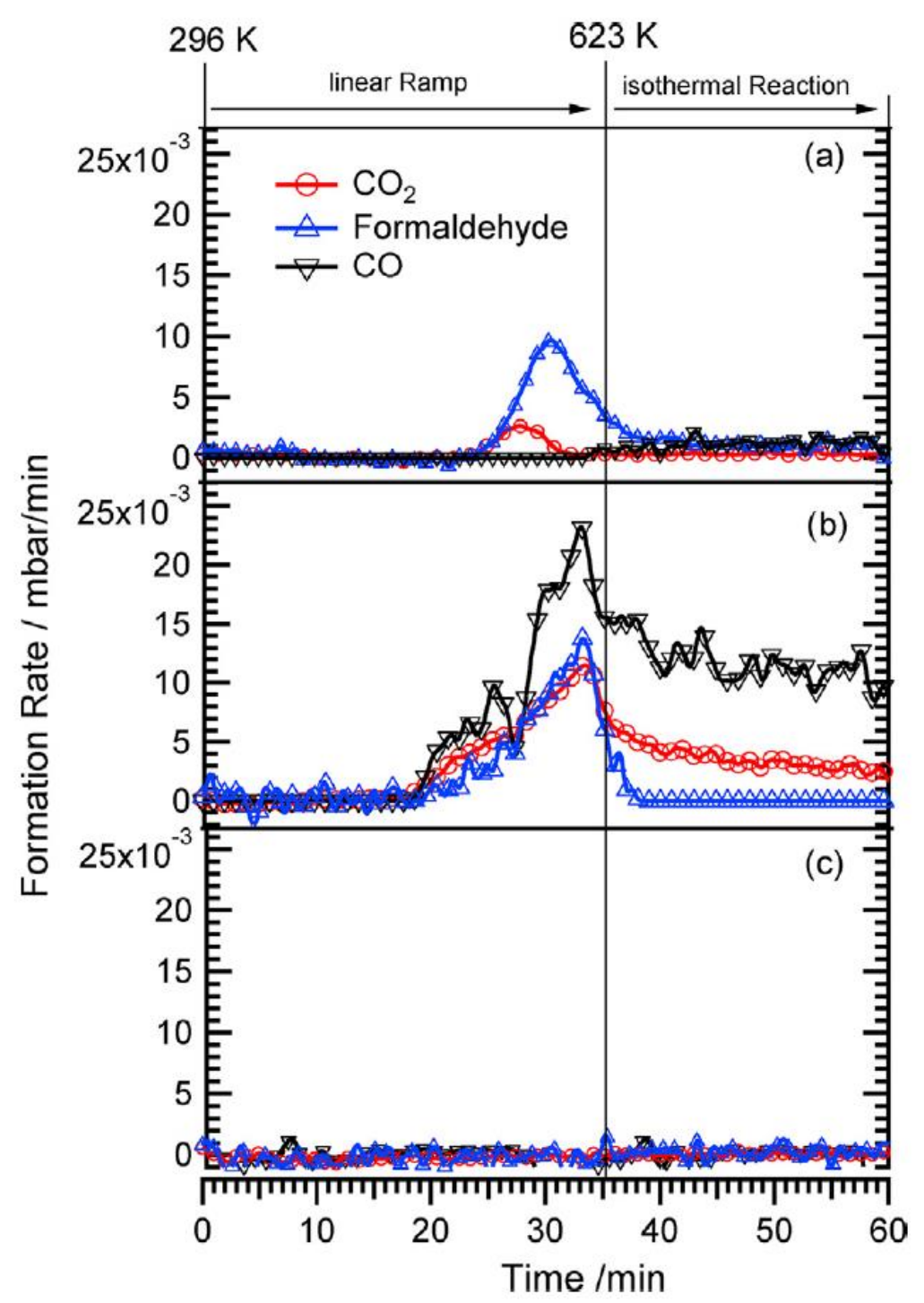

Fig. 4. MSR for (a) a clean $623 \mathrm{~K}$ annealed polycrystalline $\mathrm{Cu}$ foil; (b) a $1.8 \AA \mathrm{A} \mathrm{Cu}-$ doped oxidized $\mathrm{Zr}$ foil; and (c) a clean oxidized $\mathrm{Zr}$ foil.

As can be deduced from the low $\mathrm{CO}_{2}$-to- formaldehyde ratio of the reference experiment on pure ultra-clean $\mathrm{Cu}$ foil in Figure $4 \mathrm{a}$, the latter is able to activate methanol but not to activate water molecules. The lack of active $\mathrm{OH}$ groups on the surface obviously disables the total oxidation pathway via adsorbed formates to $\mathrm{CO}_{2}$ for maximum hydrogen generation. Moreover, clean copper cannot fully dehydrogenate adsorbed methanol, an anyway unwanted pathway that ends up in $\mathrm{CO}$ and consequently creates a catalyst poison and lowers the $\mathrm{H}_{2}$ production. Therefore, the main product is desorbed formaldehyde with a formation rate maximum of $10 \times 10^{-3} \mathrm{mbar}^{-1}$ at $580 \mathrm{~K}$, as shown in Figure 4a and reported in ref. [24]. 
The $\mathrm{CO}_{2}$ formation rate amounts to $3 \times 10^{-3} \mathrm{mbar}^{-1}$ at $550 \mathrm{~K}$ at maximum, while the $\mathrm{CO}$ formation rate is negligible over the entire experiment. Both $\mathrm{CO}_{2}$ and formaldehyde rates drop rapidly because of deactivation by further heating up to $623 \mathrm{~K}$, resulting in a total methanol conversion of around $2 \%$. In comparison, a layer of fully oxidized pure $\mathrm{ZrO}_{2}$ (Figure 4c) is not active for methanol activation and therefore neither MSR activity nor partial dehydrogenation to formaldehyde is possible. Formaldehyde, $\mathrm{CO}_{2}$ and $\mathrm{CO}$ formation rates are close to $0 \mathrm{mbar}^{-1} \mathrm{~min}^{-1}$ from 296 to $623 \mathrm{~K}$ and also in the isothermal reaction period at $623 \mathrm{~K}$ and consequently the total methanol conversion is $\sim 0 \%$.

\section{Cu-doped $\mathrm{ZrO}_{2}$ in $\mathrm{MSR}$}

As can be seen in Figure $4 b$, the selectivity pattern of pure $\mathrm{Cu}$ is shifted dramatically by electronic modification and/or phase boundary effects when both species are present at the surface at the same time: In general, $\mathrm{Cu}$-doped $\mathrm{ZrO}_{2}$ showed increased $\mathrm{CO}_{2}$ activity. However, at the same time also the full dehydrogenation pathway to $\mathrm{CO}$ is progressively opened. This leads to a mostly unselective but considerably more active catalyst compared to pure bulk copper. Figure 4 also compares the isolated $\mathrm{Cu}$ and $\mathrm{ZrO}_{2}$ catalyst components with an ultrathin $\mathrm{Cu}$ layer (nominal overlayer thickness $1.8 \AA$, Figure $4 \mathrm{~b}$ ) on $\mathrm{ZrO}_{2}$. The main product is $\mathrm{CO}$ with a maximum formation rate of $25 \times 10^{-3} \mathrm{mbar}^{-1} \mathrm{~min}^{-1}$ at $560 \mathrm{~K}$ and the full dehydrogenation pathway toward $\mathrm{CO}$ is the only one that is not completely inhibited in the isothermal reaction period. Besides $\mathrm{CO}, \mathrm{CO}_{2}$ is also formed more efficiently, indicating partial ability for water activation/total oxidation. The $\mathrm{CO}_{2}$ formation rate maximum is observed at a higher temperature of $610 \mathrm{~K}$, and amounts to $14 \times 10^{-3} \mathrm{mbar}^{\mathrm{min}^{-1}}$ which is about five times higher as compared to clean $\mathrm{Cu}$. The formaldehyde desorption rate starts to rise at the same temperature as on clean $\mathrm{Cu}$ but reaches its maximum $\left(15 \times 10^{-3} \mathrm{mbar}^{-1} \min ^{-1}\right)$ at a slightly higher temperature of $600 \mathrm{~K}$. This maximum is only slightly higher as compared to 
clean $\mathrm{Cu}$ (factor 1.5). The total methanol conversion in this experiment is approximately $7.5 \%$

Varying amounts of $\mathrm{Cu}$ on $\mathrm{ZrO}_{2}$ in $\mathrm{MSR}$

The selectivity pattern as a function of the nominal overlayer thickness of the metallic $\mathrm{Cu}$ dopant is shown in Figure 5.

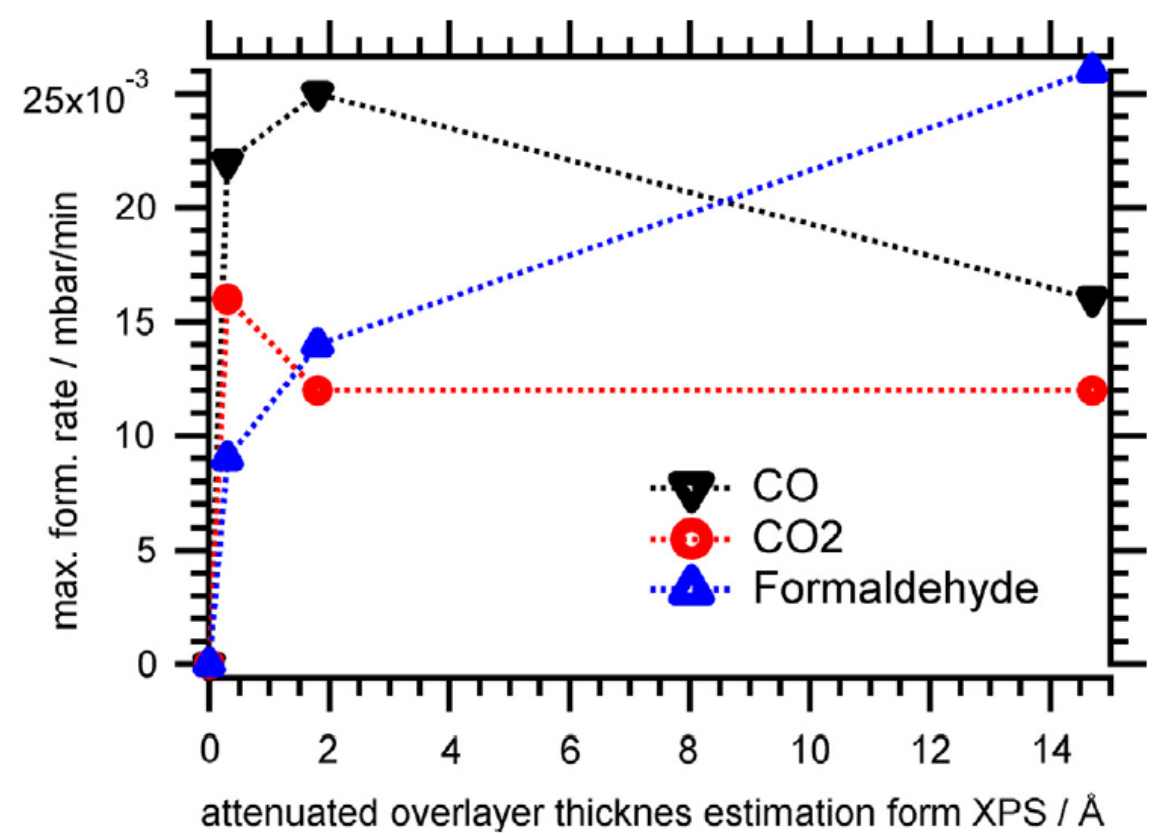

Fig. 5. $\mathrm{CO}, \mathrm{CO}_{2}$, and formaldehyde formation rates in MSR as a function of $\mathrm{Cu}$ overlayer thickness. This value was estimated by XPS using a model that assumes electron attenuation through the overlayer (for details see the Supplementary Information). The most pronounced rate differences appear between clean $\mathrm{ZrO}_{2}$ and the lowest $\mathrm{Cu}$ coverage. With higher overlayer thickness, the selectivity pattern approaches that of clean $\mathrm{Cu}$. However, some CO formation is left due to incomplete suppression of the phase boundary.

Details of the ion scattering surface ratio of $\mathrm{Cu} / \mathrm{ZrO}_{2}$ and the estimated mean particle height as derived from XPS, are given in Table 1.

Table 1: Overlayer thickness and particle height estimation for the "real" model catalysts

\begin{tabular}{|l|l|l|l|}
\hline $\begin{array}{l}\text { Evaporated amount } \\
\mathrm{Cu} / \mathrm{Hz}\end{array}$ & $\begin{array}{l}\text { LEIS ratio of } \\
\mathrm{Cu} / \mathrm{ZrO}_{2} \text { on } \\
\text { surface } / \%\end{array}$ & $\begin{array}{l}\text { attenuated overlayer } \\
\text { thickness estimation for } \mathrm{Cu} \\
\text { via XPS } / \AA\end{array}$ & $\begin{array}{l}\text { Mean particle height } \\
/ \AA\end{array}$ \\
\hline
\end{tabular}




\begin{tabular}{|c|c|c|c|}
\hline 40 & 24 & 14.7 & 61 \\
\hline 10 & 16 & 1.8 & 11 \\
\hline 2.5 & 3 & 0.3 & 10 \\
\hline
\end{tabular}

With increasing nominal overlayer thickness and a correspondingly higher ratio $\mathrm{Cu}$-to- $\mathrm{ZrO}_{2}$, all product rates approach the one for clean $\mathrm{Cu}$ foil (see above). While the formaldehyde formation rate maximum rises due to an increasing number of "pure copper" active sites for methanol activation, the $\mathrm{CO}$ and $\mathrm{CO}_{2}$ rates drop, as compared to the lowest $\mathrm{Cu}$ coverage experiment. The corresponding loss of phase boundary and, at the same time, increasing $\mathrm{Cu}$ particle size correlate mainly with a drop of the $\mathrm{CO}$ rate. Therefore, small/thin $\mathrm{Cu}$ particles/islands seem to play an important role in the formation of unwanted "full dehydrogenation" active sites which is clearly an undesirable effect in MSR for $\mathrm{H}_{2-}$ production. The mean particle height was calculated from the estimated overlayer thickness from XPS in correlation with the ratio of $\mathrm{Cu}$ on the surface from LEIS (Table 1). The results show that $\mathrm{Cu}$ does not cover $\mathrm{ZrO}_{2}$, but clearly tends to form $3 \mathrm{D}$ clusters, as deduced from the increasing nominal particle height. Consequently, a higher amount of evaporated $\mathrm{Cu}$ does not necessarily lead to an increasing amount of phase boundary but rather to an increase in height of the $\mathrm{Cu}$ islands. Due to the island height growth, the "non-phase boundary", purely metallic $\mathrm{Cu}$ area increases which is also indicated by the pure $\mathrm{Cu}$-typical higher formaldehyde rate. This is particularly obvious for the highest $\mathrm{Cu}$ coverage sample $(40 \mathrm{~Hz}, 14.7 \AA \mathrm{Cu}$ nominal overlayer thickness).

In summary, a modified catalytic behavior has been observed, but despite the enhanced $\mathrm{CO}_{2}$ formation rate achieved by partially improved water activation by phase boundary sites, the prepared surface turned out to also effectively dehydrogenate methanol to $\mathrm{CO}$. We refer this to an electronic size effect of small $\mathrm{Cu}$ particles. 


\section{2 "Inverse" model system $\mathrm{ZrO}_{2}$ and $\mathrm{ZrO}_{\mathrm{x}} \mathrm{H}_{\mathrm{y}}$ on $\mathrm{Cu}$}

For the "inverse" model system we prepared zirconia layers of various nominal thickness on the same polycrystalline $\mathrm{Cu}$ foil (99.999\%) by our UHV compatible sputtering technique [20]. The $\mathrm{Zr}$ oxidation state was controlled by varying the reactive sputtering conditions, i.e. by controlling oxygen-containing species in the background gas (see experimental section). Hence, we prepared not only zirconia layers but also layers consisting of both zirconia and metallic $\mathrm{Zr}$. These not fully oxidized $\mathrm{Zr}$ layers on $\mathrm{Cu}$ showed favorable catalytic abilities when used as a pre-catalyst for methanol steam reforming reactions by forming suitable active sites under in-situ conditions by in-situ hydroxylation $\left(\mathrm{ZrO}_{\mathrm{x}} \mathrm{H}_{\mathrm{y}}\right)$. As for the "real" model system, ion scattering was performed to prove the co-existence of $\mathrm{Cu}$ and $\mathrm{Zr}$ on the surface (Figure 2, lower panel).

\section{Fully oxidized $\mathrm{Zr}$ on $\mathrm{Cu}$ in MSR}

In the first series of experiments, we prepared fully oxidized zirconia layers. At a fractional coverage of around $0.2 \mathrm{ML}$, as derived from the non-attenuated XPS coverage model, an estimated thickness (from the attenuated XPS estimation) of $1.3 \AA$ was obtained. Moreover, multilayers with thicknesses up to $1.2 \mathrm{~nm}(8.8 \mathrm{ML})$ were prepared. In analogy to the experiment of Figure 3, neither pure $\mathrm{Cu}$ nor $\mathrm{ZrO}_{2}$ itself shows any "full" dehydrogenation activity of methanol to $\mathrm{CO}$. Interestingly, none of the "inverse" $\mathrm{Cu}-\mathrm{ZrO}_{2}$ and $\mathrm{ZrO}_{\mathrm{x}} \mathrm{H}_{\mathrm{y}}$ model catalysts opened this pathway. In contrast to the $\mathrm{Cu}$-nano-islands on the bulk $\mathrm{ZrO}_{2}$ layer shown before, the "inverse" $\mathrm{ZrO}_{2} / \mathrm{ZrO}_{\mathrm{x}} \mathrm{H}_{\mathrm{y}}$ phase boundary on bulk $\mathrm{Cu}$ does not favor the undesired full dehydrogenation reaction channel. Therefore, only the $\mathrm{CO}_{2}$-reaction rate and the formaldehyde rate are used to determine the performance and selectivity of the model catalysts. 
As shown in Figure 6a, a much higher $\mathrm{CO}_{2}$ selectivity could be observed on the "inverse" $\mathrm{Cu}$ $\mathrm{ZrO}_{2}$ catalyst than on the pure $\mathrm{Cu}$ support, where formaldehyde is always the main product.

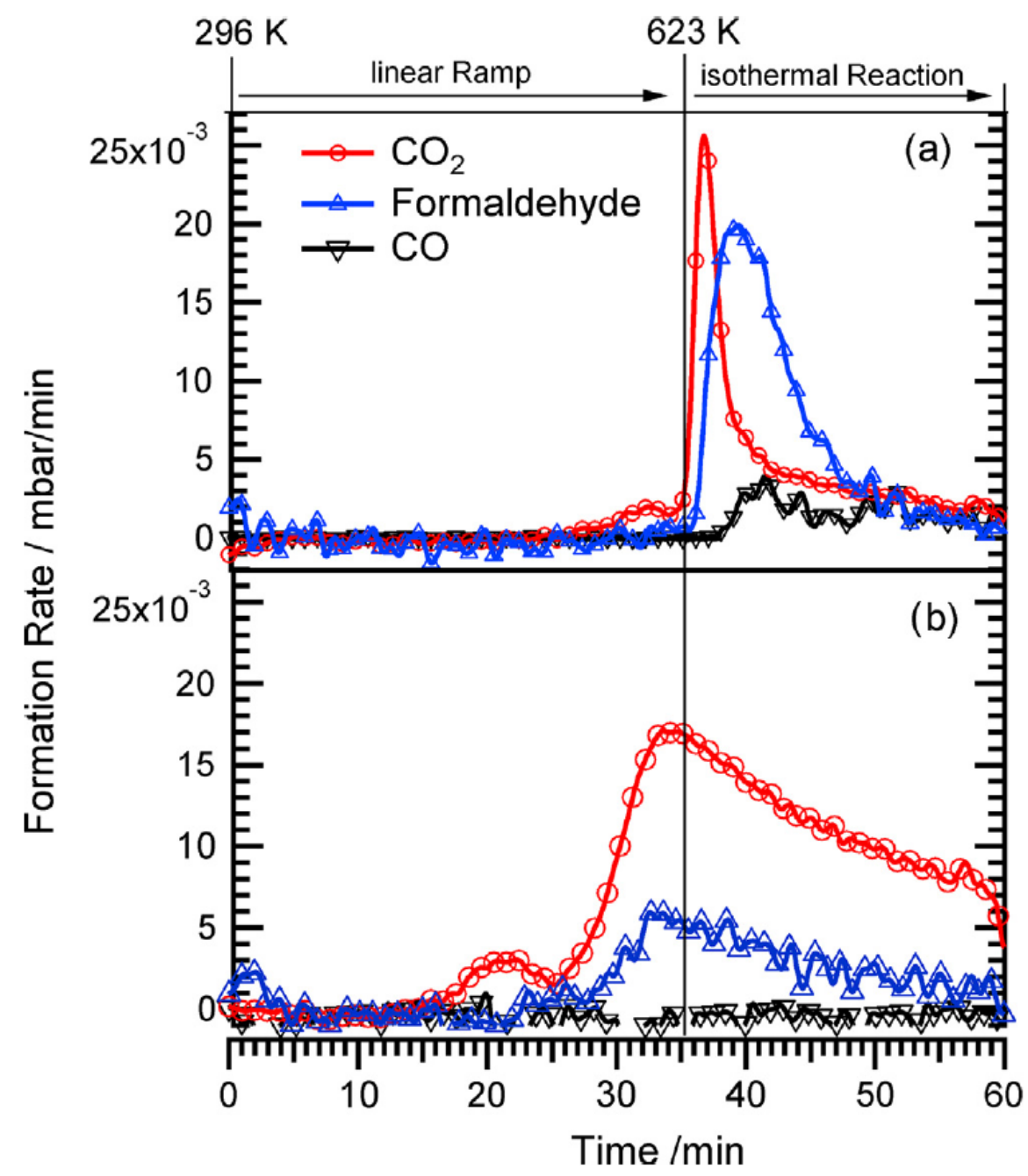

Fig. 6. MSR for (a) a Cu foil with $8 \AA \mathrm{ZrO}_{2}$ overlayer; (b) a Cu foil with a partially oxidized $\mathrm{Zr}$ overlayer (thickness: $1 \AA$ ). The formation of hydroxylated $\mathrm{Zr}$ species $\left(\mathrm{ZrO}_{x} \mathrm{H}_{y}\right)$ occurs under reaction conditions in situ.

The shown catalytic experiments were performed on a fully oxidized $\sim 1.4 \AA \mathrm{ZrO}_{2}$-doped $\mathrm{Cu}$ foil. The $\mathrm{CO}_{2}$ rate amounted up to $27 \times 10^{-3} \mathrm{mbar}^{-1} \mathrm{~min}^{-1}$, that is more than eight times the rate on clean $\mathrm{Cu}\left(3 \times 10^{-3} \mathrm{mbar}^{-1} \mathrm{~min}^{-1}\right)$. In addition, the formaldehyde rate maximum is at $20 \times 10^{-3}$ mbar $\min ^{-1}$ higher than on clean $\mathrm{Cu}$, but only by a factor of 2 . Both rate maxima are reached in the isothermal reaction period and only very low formation rates could be determined around $580 \mathrm{~K}$. The total methanol conversion at the end of the isothermal reaction period is 
$\sim 4 \%$. Interestingly, very fast deactivation both of $\mathrm{CO}_{2}$ and formaldehyde formation was observed.

Both the formaldehyde rate as well as the $\mathrm{CO}_{2}$ formation rate increase with $\mathrm{ZrO}_{2}$ doping whereas the $\mathrm{CO}_{2}$ rate is even more influenced. This makes $\mathrm{CO}_{2}$ the main product on samples with a $\mathrm{ZrO}_{2}$ film thickness between 1 and $8 \AA$. Higher coverages make the catalyst more and more behave like bulk $\mathrm{ZrO}_{2}$ (Figure 7), most likely caused by a loss of interface and therefore a loss of bi-functionality of the catalytic surface.

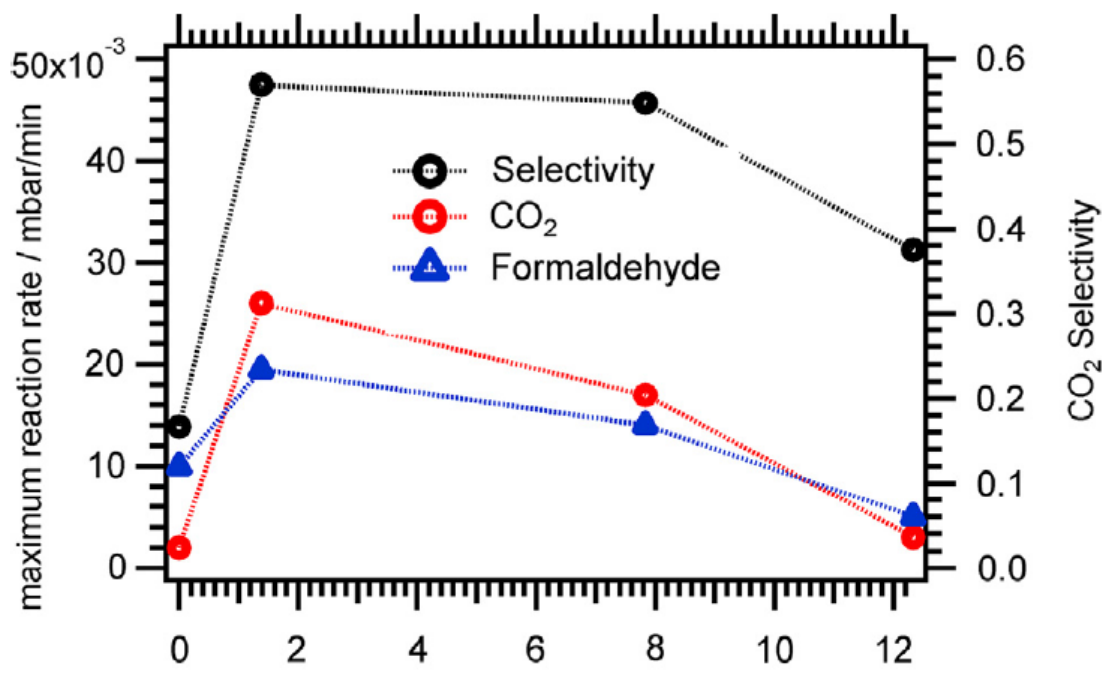

attenuated overlayer thickness estimation from XPS / Angström

Fig. 7. $\mathrm{CO}, \mathrm{CO}_{2}$, and formaldehyde formation rates in MSR as a function of the deposited amount of fully oxidized $\mathrm{ZrO}_{2}$. Overlayer thickness was estimated by XPS using a model that assumes electron attenuation through the overlayer (for details see the Supplementary Information). Starting with clean $\mathrm{Cu}$, the selectivity pattern changes in the fractional coverage regime and approaches the inactive state of $\mathrm{ZrO}_{2}$ at high coverages.

Interpretation of these results suggest an important influence of $\mathrm{ZrO}_{2}$ on the way how the individual reaction channels are steered. Since pure $\mathrm{Cu}$ or pure $\mathrm{ZrO}_{2}$ are either unable to activate water and to provide weakly bound $\mathrm{OH}$-groups for reaction with activated $\mathrm{C}_{1}$-fuel or unable to activate methanol, the beneficial $\mathrm{Cu}-\mathrm{ZrO}_{2}$ interaction gives access to this desired reaction route (Figure 6a). This result can in principle be interpreted in terms of two phenomena; one describes the mechanism via a phase boundary phenomenon where the 
availability of activated water on the surfaces suppresses formaldehyde desorption from the catalytic surface because of the competitive reaction of formaldehyde with $\mathrm{OH}$-groups and a consequently opened total oxidation pathway to $\mathrm{CO}_{2}$. A quantitative loss of phase boundary therefore results in a loss of $\mathrm{CO}_{2}$-selectivity. With higher coverage, the $\mathrm{ZrO}_{2}$ island area increases and, as soon as the island coalesce, the $\mathrm{Cu}-\mathrm{ZrO}_{2}$ phase boundary decreased again, explaining the loss of activity with nominally thicker zirconia layers. The second effect that may be speculated to play a role in the selectivity increase by $\mathrm{Cu}-\mathrm{ZrO}_{2}$ interaction is the potential electronic modification of ultrathin zirconia layers by the $\mathrm{Cu}$ support [37]. This new electronic state may enable the above-mentioned changes in activity/selectivity likely because of favorable reversible adsorption properties of the reactants. A higher $\mathrm{ZrO}_{2}$ coverage in this case also leads to lower activity because $\mathrm{ZrO}_{2}$ at some point gets too thick to be electronically modified by the $\mathrm{Cu}$ substrate.

The crucial importance of the $\mathrm{Cu}-\mathrm{ZrO}_{2}$ phase boundary, as compared to an exclusive "ligand" effect of $\mathrm{Cu}$ on the thin $\mathrm{Zr}$-oxide layers, is suggested by the fact that higher coverages of $\mathrm{ZrO}_{2}$ lead to a decrease of the formaldehyde rate. Formaldehyde is, as shown in Figure 3a ("real" model system), mostly a product stemming from the clean $\mathrm{Cu}$ surface. Therefore, clean $\mathrm{Cu}$ surface gets progressively lost with increasing $\mathrm{ZrO}_{2}$ coverage. This effect is becoming predominant if the $\mathrm{ZrO}_{2}$ islands get larger with respect to their $\mathrm{Cu}$-covering area instead of becoming higher. If they become both larger with respect to covering area and higher, an electronic $\mathrm{Cu}$-substrate influence of the thin oxide and consequently beneficial adsorption energies may combine with the extended phase boundary dimensions in a favorable manner.

The overall surface activity increases with $\mathrm{ZrO}_{2}$ deposition. This can, to some extent, be assigned to a "sputter-effect" on the $\mathrm{Cu}$ surface during preparation by $\mathrm{ZrO}_{2}$ and a consequently activated $\mathrm{Cu}$ surface. However, the enhanced selectivity can for sure be assigned to the beneficial $\mathrm{Cu}-\mathrm{ZrO}_{2}$ interaction in view of the fact that $\mathrm{Ar}^{+}$sputtered $\mathrm{Cu}$ is 
somewhat more active but still shows the same (formaldehyde selective) product pattern (see Figure S1 in the Supplementary Information).

\section{Characterization by ex-situ XPS/AES before and after MSR}

Figure 8 shows the XPS and AES spectra before and after the MSR experiments on the “inverse" $\mathrm{Cu}-\mathrm{ZrO}_{2}$ catalyst shown Figure 6a.

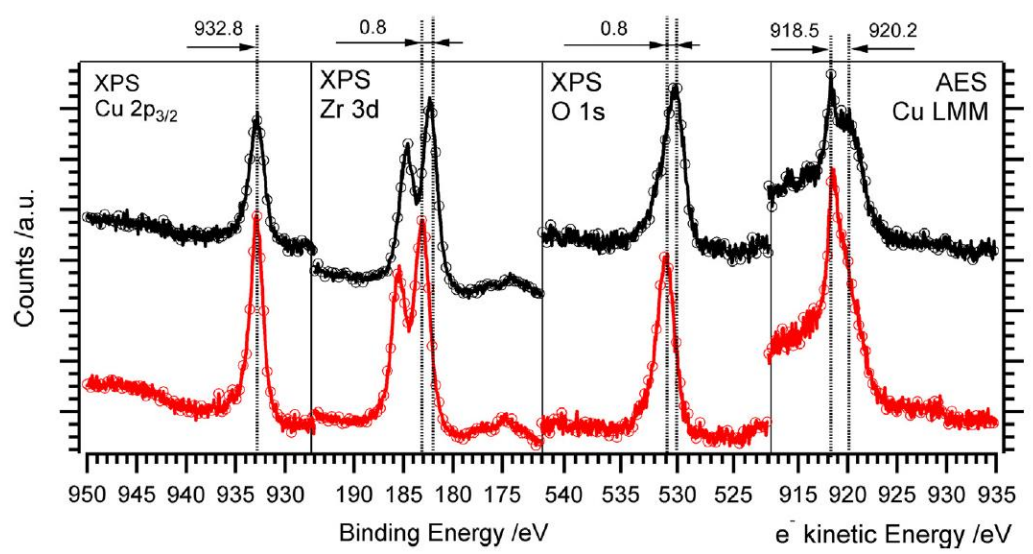

Fig. 8. XPS spectra of the fully oxidized $\mathrm{ZrO}_{2}$ on $\mathrm{Cu}$ "inverse" model catalyst system before and after MSR (shown in Fig. 6a). The Cu2p $p_{3 / 2}$ peak is not very sensitive to the ongoing $\mathrm{Cu}^{0} / \mathrm{Cu}^{+}$redox chemistry. The AES fingerprint indicates $\mathrm{Cu}^{+}$and $\mathrm{Cu}^{2+}$ species. The peak shift of $\mathrm{Zr} 3 d$ correlates with the O1s shift and therefore suggests structural changes in the $\mathrm{ZrO}_{2}$ overlayer $\left(\mathrm{ZrO}_{2}\right.$ particle size/shape effects).

We observed a peak shift of $0.5-0.8 \mathrm{eV}$ of the $\mathrm{Zr} 3 \mathrm{~d}$ doublet towards lower binding energies after the MSR experiments (the $\mathrm{Zr}$ 3d binding energy cannot be determined more precisely due to charging issues) (Figure 8, panel 2). Exactly the same peak shift is observed for the $\mathrm{O}$ 1s peak (Figure 8 panel 3). Therefore, this shift cannot be correlated to chemical $\mathrm{Zr}$ reduction but most likely can be assigned to overlayer shape effects and thus altered charging effects. It is known that small islands of a oxide species can differ in XPS binding energies from the respective bulk [35], however, charging must play a role in the insulating $\mathrm{ZrO}_{2}$ systems too, especially if the $\mathrm{ZrO}_{2}$ islands cluster towards 3D particle shapes. These structural changes occur at $623 \mathrm{~K}$ under reaction conditions (total pressures 1 bar) and can also be correlated to the catalytic results, where fast deactivation over time triggers a sharp drop of all reactions rates in the isothermal part. It is also worth mentioning, that the $\mathrm{CO}_{2}$ formation clearly rises in 
advance of the formaldehyde formation (Figure 6a). A possible explanation can be given in terms of the stability and wetting behaviour of the $\mathrm{ZrO}_{2}$ islands: at the beginning, a thin $\mathrm{ZrO}_{2}$ layer with the above described extended $\mathrm{Cu} / \mathrm{ZrO}_{2}$ phase boundary is MSR active but apparently not structurally stable. Clean $\mathrm{Cu}$ surface grows as a result of $\mathrm{ZrO}_{2} 3 \mathrm{D}$ cluster formation, resulting in the observed $\mathrm{Zr} 3 \mathrm{~d}$ and $\mathrm{O}$ 1s peak shifts, rapid deactivation and a selectivity shift to formaldehyde (Figure 6a, 35-50 min reaction time).

The overall oxygen coverage slightly increases after MSR on all samples as derived from the XPS coverage model. This is a clear evidence for the oxidation effect of water activation. $\mathrm{Cu}^{+}$-Oxides that form during MSR can not been detected with XPS due to hardly distinguishable $\mathrm{Cu}^{+}$and $\mathrm{Cu}^{0}$ species and the insufficient surface sensitivity of this method. With AES, a method that is more surface sensitive (a detailed description of the surface sensitivity of the used techniques can be found in ref. [26]), a change in the Cu LMM fingerprint indicates the partial formation of different oxidation states under MSR conditions (Figure 8, panel 4). Coking is not an issue since on any catalyst system of this study all carbon residues after MSR were below the XPS detection limit.

$\mathrm{Zr}^{0}$ containing pre-catalyst

By minimizing the oxygen content of the Ar sputter atmosphere, a mixed layer consisting of metallic and oxidized $\mathrm{Zr}$ was prepared. The corresponding XPS $\mathrm{Zr}$ 3d region is shown in Figure 9. 


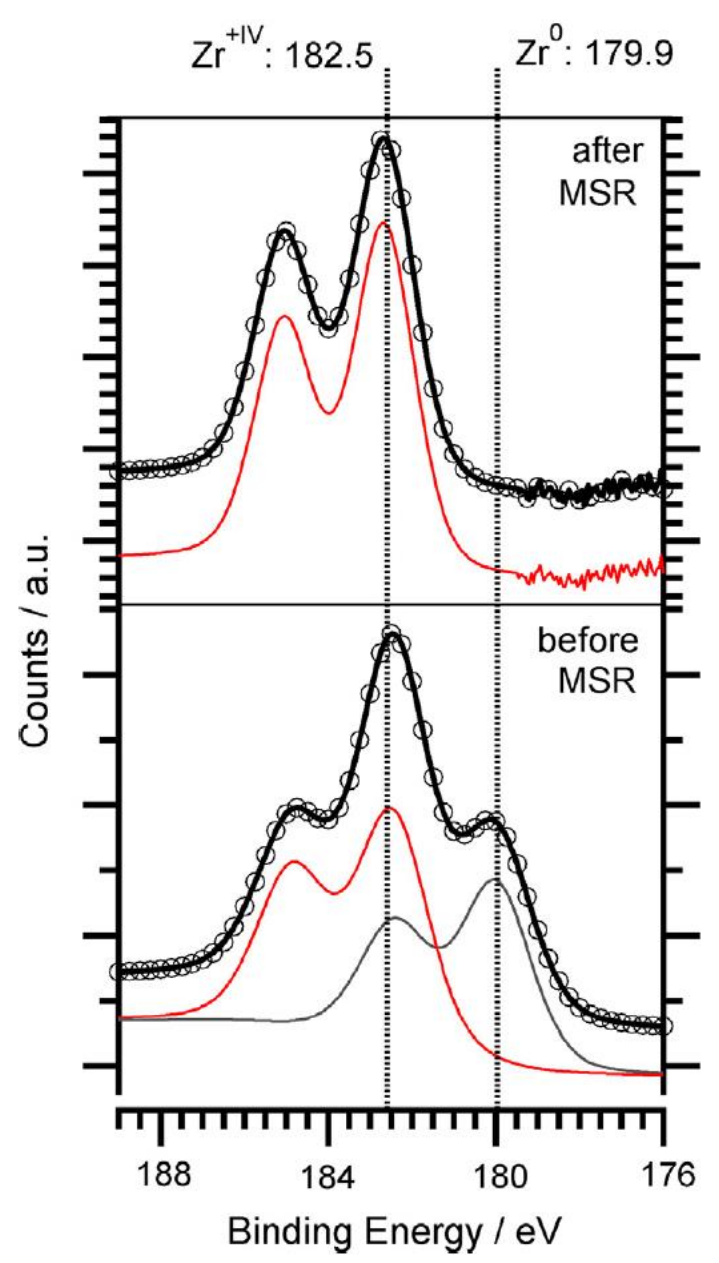

Fig. 9. XPS $\mathrm{Zr} 3 d$ region of the mixed $\mathrm{Zr}^{+1 \mathrm{~V}} / \mathrm{Zr}^{0}$ overlayer on $\mathrm{Cu}$ before and after MSR.

In analogy to the $\mathrm{CuZn}$ system, oxidative segregation of metallic $\mathrm{Zr}$ from the pre-catalyst under reaction conditions is believed to form a maximum of phase boundary [24]. The in-situ oxidation is performed by water and the formed species are identified to be $\mathrm{Zr}$-hydroxide species $\left(\mathrm{ZrO}_{\mathrm{x}} \mathrm{H}_{\mathrm{y}}\right)$ as shown by related HREELS experiments (Figure 10). 


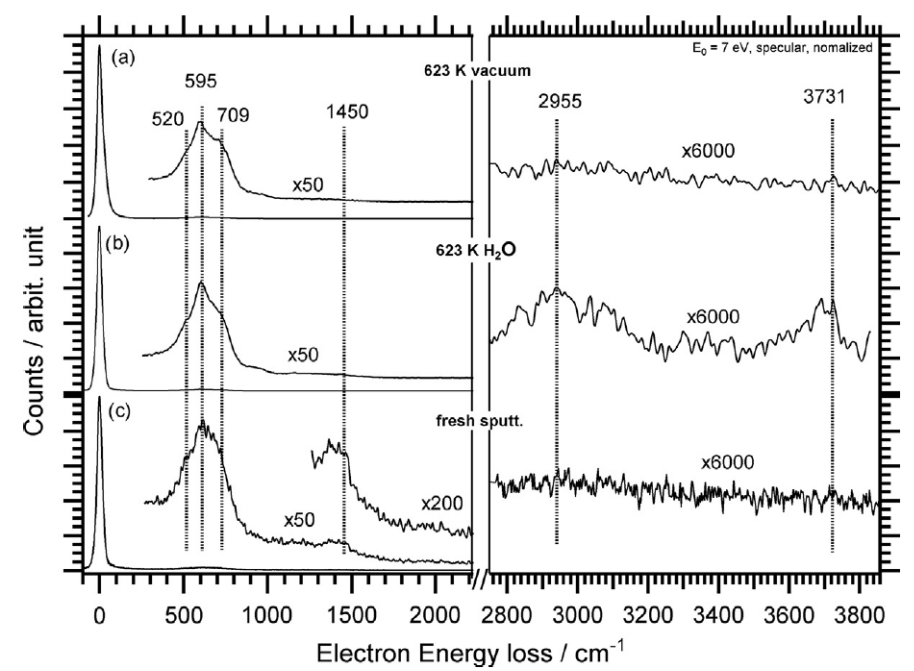

Fig. 10. HREEL spectra of the mixed $\mathrm{Zr}^{+\mathrm{IV}} / \mathrm{Zr}^{0}$ overlayer (c) on a $\mathrm{Cu}(111)$ single crystal. Hydroxylation (b) in water leads to zirconium hydroxyde $\left(v_{\mathrm{Zr}-\mathrm{OH}}\right.$ : $\left.3731 \mathrm{~cm}^{-1}\right)$. (a) Annealing in vacuum and consequent loss of OH groups. Primary counts and FWHM: (a) $1.6 \times 10^{5} \mathrm{cps} / 33 \mathrm{~cm}^{-1}$; (b) $9.0 \times 10^{4} \mathrm{cps}_{3} / 34 \mathrm{~cm}^{-1}$; (c) $5.9 \times 10^{3} \mathrm{cps} / 36 \mathrm{~cm}{ }^{-1}$. Cu-O vibrations due to partial oxidation of the substrate during the reaction contribute in a minor way to the $\mathrm{Zr}-\mathrm{O}$ vibrations around $600 \mathrm{~cm}^{-1}$. A reference spectrum for Cu-O can be found in the Supplementarv Information.

This hydroxylation could not be seen on the previously described $\mathrm{ZrO}_{2}$ (initially fully oxidized) zirconia catalysts. The $\mathrm{Zr}-\mathrm{O}$ vibrations occur in the area between 550 and $750 \mathrm{~cm}^{-1}$ [38] and the second harmonics with the double wavenumber below $1500 \mathrm{~cm}^{-1}$. In correlation with the XPS experiments, the freshly prepared sample contains $\mathrm{ZrO}_{2}$, explaining the $\mathrm{Zr}-\mathrm{O}$ modes in HREELS. As soon as this sample is exposed to water $\left(5 \times 10^{-5} \mathrm{mbar}, 623 \mathrm{~K}, 15 \mathrm{~min}\right)$, a $\mathrm{Zr}-\mathrm{OH}$ vibration at about $3731 \mathrm{~cm}^{-1}$ [39] appears due to oxidative hydroxylation of metallic $\mathrm{Zr}$. At the same time, the XPS peak assigned to $\mathrm{Zr}^{0}$ in the $\mathrm{Zr} 3 \mathrm{~d}$ region disappears. This provides clear evidence that the originally metallic $\mathrm{Zr}$ constituent is now fully oxidized/hydroxylated. These hydroxyl groups are not stable in vacuum at $623 \mathrm{~K}$. Apparently because of reversible re-hydroxylation under reaction conditions, access to effective water adsorption/activation is gained and the catalytic behavior of this system is significantly different compared to the initially fully "dry" oxidized "inverse" $\mathrm{ZrO}_{2}$ pre-catalysts (catalytic experiment in Figure 6b). Note that HREELS was performed on a $\mathrm{Cu}(111)$ single crystal while the catalytic experiments were performed on a polycrystalline $\mathrm{Cu}$ foil (compare experimental section). To ensure comparability of the experiments, analysis by XPS was performed on both samples with the same results (shown in Figure 9 for the $\mathrm{Zr} 3 \mathrm{~d}$ region on the polycrystalline $\mathrm{Cu}$ foil). As the major catalytic effect, $\mathrm{CO}_{2}$ formation starts at lower 
temperature $(\sim 530 \mathrm{~K})$. Formaldehyde formation is suppressed and the catalyst is more stable with respect to self-deactivation (Figure 6b). The $\mathrm{CO}_{2}$ maximum formation rate amounts to $18 \times 10^{-3} \mathrm{mbar}^{-1} \mathrm{~min}^{-1}$ at $610 \mathrm{~K}$ and decreases only slightly in the isothermal reaction period. The formaldehyde formation rate maximum occurs at the same temperature, around $610 \mathrm{~K}$, but is smaller $\left(6 \times 10^{-3} \mathrm{mbar}^{-1} \mathrm{~min}^{-1}\right)$. No $\mathrm{CO}$ at all was detected and the total methanol conversion is around $5 \%$. Compared to clean $\mathrm{Cu}$, the $\mathrm{CO}_{2}$ rate is increased by a factor 6 , while the formaldehyde rate is decreased by a factor of 2 . The $\mathrm{CO}_{2}$ selectivity at the rate maxima ( 600 $\mathrm{K}$ ) is higher than $75 \%$. Optimization of the degree of hydroxylation and $\mathrm{Zr}-\mathrm{OH}$ coverage have an extremely high potential to improve the selectivity pattern and are focus of further studies.

In general, strong evidence was found that hydroxylated/oxidic species of $\mathrm{Zr}$ are highly suitable for a promotional phase boundary interaction with $\mathrm{Cu}$. An initially partially bimetallic pre-catalyst forms highly active and selective sites under realistic in-situ catalytic conditions.

\section{Discussion}

Catalytic results and estimated turn over frequencies for all prepared catalysts are summed up in Table 2.

Table 2: Summary of all reaction rates and surface analysis data that were used for estimation of turnover frequencies. Since no quantitave perimeter information is available and the activation of methanol only takes place on $\mathrm{Cu}$ and not on $\mathrm{ZrO}_{2}$, TOF value estimations are based on blank $\mathrm{Cu}$ surface sites calculated from ion scattering data. The ratio of $\mathrm{Cu} / \mathrm{Zr}$ was determined under consideration of relative sensitivity factors for LEIS by measuring the clean $\mathrm{Cu}$ and $\mathrm{ZrO}_{2}$ surfaces. The overlayer thickness was calculated from XPS using an attenuated overlayer model (detail see SI). 


\begin{tabular}{|c|c|c|c|c|c|c|c|c|c|c|}
\hline & \multirow{2}{*}{$\begin{array}{c}\text { Over- } \\
\text { layer } \\
\text { thick- } \\
\text { ness /A }\end{array}$} & \multicolumn{2}{|c|}{$\mathrm{Cu}$ ratio } & \multirow{2}{*}{$\begin{array}{c}\text { Estimated } \\
\text { number of } \\
\text { surface } \\
\mathrm{Cu} \text { sites }\end{array}$} & \multicolumn{3}{|c|}{ 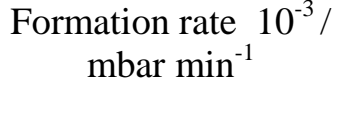 } & \multicolumn{3}{|c|}{$\begin{array}{c}\text { Turnover frequency } \\
\text { based on surface } \mathrm{Cu} \\
\text { sites } / \mathrm{s}^{-1}\end{array}$} \\
\hline & & XPS & LEIS & & $\mathrm{CO}_{2}$ & $\mathrm{H}_{2} \mathrm{CO}$ & $\mathrm{CO}$ & $\mathrm{CO}_{2}$ & $\mathrm{H}_{2} \mathrm{CO}$ & $\mathrm{CO}$ \\
\hline $\mathrm{Cu}$ & - & 1 & 1 & $1.35 \times 10^{16}$ & 3 & 10 & - & 0.03 & 0.09 & - \\
\hline \multirow{3}{*}{$\begin{array}{l}\mathrm{Cu} \text { on } \\
\mathrm{ZrO}_{2} \\
\text { „real““ }\end{array}$} & 14.7 & 0.72 & 0.24 & $3.24 \times 10^{15}$ & 13 & 26 & 16 & 0.46 & 0.92 & 0.57 \\
\hline & 1.8 & 0.23 & 0.16 & $2.16 \times 10^{15}$ & 14 & 15 & 25 & 0.75 & 0.80 & 1.33 \\
\hline & 0.3 & 0.05 & 0.03 & $4.05 \times 10^{14}$ & 16 & 9 & 23 & 4.55 & 2.56 & 6.54 \\
\hline \multirow{3}{*}{$\begin{array}{c}\mathrm{ZrO}_{2} \text { on } \\
\mathrm{Cu} \\
\text { „inverse““ }\end{array}$} & 12.3 & 0.23 & 0.12 & $1.62 \times 10^{15}$ & 3 & 5 & - & 0.21 & 0.36 & - \\
\hline & 7.8 & 0.45 & 0.17 & $2.35 \times 10^{15}$ & 17 & 14 & 1 & 0.83 & 0.69 & 0.05 \\
\hline & 1.4 & 0.90 & 0.64 & $8.61 \times 10^{15}$ & 27 & 20 & 3 & 0.35 & 0.26 & 0.04 \\
\hline $\begin{array}{c}\mathrm{ZrO}_{x} \mathrm{H}_{y} \\
\text { on } \mathrm{Cu}\end{array}$ & 0.8 & 0.95 & 0.80 & $1.07 \times 10^{16}$ & 18 & 6 & - & 0.19 & 0.06 & - \\
\hline $\mathrm{ZrO}_{2}$ & - & 0 & 0 & 0 & 0 & 0 & 0 & 0 & 0 & 0 \\
\hline
\end{tabular}

TOF values are calculated by considering all surface $\mathrm{Cu}$ sites as active sites. This approach was considered to be most efficient because of the fact that perimeter information of $\mathrm{Cu} / \mathrm{ZrO}_{\mathrm{x}} \mathrm{H}_{\mathrm{y}}$ islands are unavailable due to the experimental setup. The comparison of the "real" und "inverse" $\mathrm{Cu}(\mathrm{ox}) / \mathrm{Zr}(\mathrm{ox})$ model pre-catalysts for methanol steam reforming points out that in both cases active sites are formed under reaction conditions providing the desired bi-functionality. Therefore, this interaction is proven to be extremely relevant for fuel reforming processes. By varying the interface with respect to chemical and topological aspects, the selectivity pattern and stability of the catalysts can be beneficially shifted. The oxidation state of the $\operatorname{Zr}(\mathrm{ox})$ component turned out to be highly relevant for fuel activation and in further consequence for increasing the $\mathrm{CO}_{2}$ rate. Especially in the "real" model system, where the surface zirconium was in any case fully oxidized to form a closed and uniform zirconia layer, only little improvements in the $\mathrm{CO}_{2}$ rate compared to the "inverse" model catalyst studies could be achieved. The reactively sputtered $\mathrm{ZrO}_{2}$ layers (fully oxidized) with a fractional coverage on polycrystalline $\mathrm{Cu}$ formed an already more active phase boundary. We suppose this layer to be less uniform and more defect-rich simply due to non-uniform oxidation while sputtering und structural irregularities because of the relatively high (kinetic) impact energy of sputtered $\mathrm{ZrO}_{\mathrm{x}}$. However, all $\mathrm{Zr}$ was found to be in the $+\mathrm{IV}$ state and none of these catalysts form a stable phase boundary that continuously activates water. Rather 
clustering, loss of phase boundary and therefore rapid deactivation was observed. To fulfil the requirement of dynamic water activation, the oxidation state of zirconium in the pre-catalyst needs to be varied as shown in the mixed $\mathrm{Zr}^{0} / \mathrm{ZrO}_{2}$ "inverse" system. Only oxidative segregation of $\mathrm{ZrO}_{x} \mathrm{H}_{\mathrm{y}}$ under MSR conditions leads to the interface that is in the appropriate chemical state for fast and efficient reversible water splitting and is also stable under isothermal operating conditions of the catalyst. It needs to be emphasized that the involved hydroxylated oxidation state that forms the $\mathrm{CO}_{2}$-selective phase boundary to $\mathrm{Cu}$ is also a $\mathrm{Zr}^{+\mathrm{IV}}$ state.

Regarding the unwanted $\mathrm{CO}$ formation rate a comparison of the results is also highly interesting since only the "real" system ( $\mathrm{Cu}$-nano islands on bulk $\mathrm{ZrO}_{2}$ ) catalyzes the full dehydrogenation pathway. None of the pure constituents can do so. Therefore, this undesired pathway is most likely opened by the small $\mathrm{Cu}$ particles. $\mathrm{A} \mathrm{Cu}$ particle/island size effect of nano- $\mathrm{Cu}$ itself is apparently not documented in literature, likely because such extremely small $\mathrm{Cu}$ particles $(\sim 1 \mathrm{~nm}$ in size) are unlikely to be studied experimentally on supported catalyst systems. Nevertheless, we may draw the conclusion that the formation of too finely dispersed $\mathrm{Cu}$ at least on zirconia as a support should be avoided when preparing a $\mathrm{Cu} / \mathrm{ZrO}{ }_{2} \mathrm{MSR}$ catalyst.

Formaldehyde was formed an all $\mathrm{Cu}$ containing samples since formaldehyde desorption is the known main route on clean copper [24]. The formation rate is proportional to the area of clean copper. In the presence of the efficiently water activating $\mathrm{ZrO}_{\mathrm{x}} \mathrm{H}_{\mathrm{y}} / \mathrm{Cu}$ phase boundary, the reaction channel through formates towards $\mathrm{CO}_{2}$ is open and therefore the amount of desorbed formaldehyde is significantly decreased (factor 2).

Our studies clearly show that the control of the quality of the prepared phase boundaries it is highly relevant to steer the $\mathrm{CO}_{2}$-selectivity in MSR. An interface that triggers full dehydrogenation to $\mathrm{CO}$ and total oxidation to $\mathrm{CO}_{2}$, as observed for the "real" model catalyst 
system, needs to be avoided, while special phase boundary $\mathrm{ZrO}_{\mathrm{x}} \mathrm{H}_{\mathrm{y}} / \mathrm{Cu}$ sites, as present in the "inverse" catalyst, are highly beneficial for $\mathrm{CO}_{2}$-selectivity. The knowledge about the quality of differently prepared phase boundary types, and the control of the activation of different reaction pathways via the chosen preparation technique is an important input toward the optimization of technologically relevant real catalytic systems.

A comparison with the well-known CuZn system shows that the presented system is less active than $\mathrm{CuZn}\left(\mathrm{CO}_{2}\right.$ formation rate around $0.6 \mathrm{mbar}^{-1} \mathrm{~min}^{-1}$ in Ref [24]) and comparably $\mathrm{CO}_{2}$-selective. Rietzkopf et. al. [40] conclude from wet-chemical prepared catalysts, that $\mathrm{Cu}$ $\mathrm{Zr}$ phase boundary has an even higher potential for $\mathrm{CO}_{2}$-selectivity. Compared with $\mathrm{PdZn}$, a higher $\mathrm{CO}_{2}$ rate could be achieved ( 0.013 $\mathrm{mbar}^{-1} \mathrm{~min}^{-1} \mathrm{CO}_{2}$ on PdZn in Ref. [22]). While the $\mathrm{CO}_{2}$ selectivity is pertained over the entire temperature range for the $\mathrm{Cu}-\mathrm{Zr}$ system, the $\mathrm{PdZn}$ system shows strong $\mathrm{CO}$ formation above $573 \mathrm{~K}$ reaction temperature.

\section{Conclusion}

Small $\mathrm{Cu}$ particles/islands on a bulk $\mathrm{ZrO}_{2}$ substrate exhibit a different selectivity pattern compared to bulk $\mathrm{Cu}$ and "inverse" $\mathrm{ZrO}_{2}$ or $\mathrm{ZrO}_{\mathrm{x}} \mathrm{H}_{\mathrm{y}}$ on $\mathrm{Cu}$ catalysts. The full dehydrogenation pathway that is not observed on bulk $\mathrm{Cu}$ is opened. Therefore, the desired $\mathrm{CO}_{2}$ selectivity can hardly be increased in this system. The more $\mathrm{Cu}$ was deposited on $\mathrm{ZrO}_{2}$, the more it behaves like bulk $\mathrm{Cu}$, exhibiting an increasing formaldehyde formation rate, a low $\mathrm{CO}_{2}$ and an even lower CO formation rate.

Freshly sputtered, fully oxidized $\mathrm{ZrO}_{2}$ on $\mathrm{Cu}$ temporarily increases the $\mathrm{CO}_{2}$ selectivity but is not forming a stable catalyst under reaction conditions. Due to $\mathrm{ZrO}_{2}$ clustering the formation rates $\left(\mathrm{CO}_{2}, \mathrm{CO}\right.$, formaldehyde) converge to zero in the isothermal reaction period. 
By preparing (partially) hydroxylated $\mathrm{ZrO}_{\mathrm{x}} \mathrm{H}_{\mathrm{y}}$ on $\mathrm{Cu}$, the $\mathrm{CO}_{2}$ selectivity becomes significantly increased. $\mathrm{CO}$ formation is completely suppressed and a small remaining formaldehyde rate due to the intrinsic activity of the $\mathrm{Cu}$ surface was detected. The MSRpromotional hydroxylation of $\mathrm{Zr}^{0}$ was proven by HREEL spectra, clearly showing a $\mathrm{Zr}-\mathrm{OH}$ vibration mode at about $3650 \mathrm{~cm}^{-1}$.

Therefore, a bi-functional $\mathrm{Cu} / \mathrm{ZrO}_{\mathrm{x}} \mathrm{H}_{\mathrm{y}}$ surface was identified with enhanced selectivity for fuel reforming of methanol. Quantitative optimization using other preparation techniques such as ALD to increase the ratio of hydroxylated $\mathrm{Zr}$ as well as tests with intermetallic $\mathrm{Cu} / \mathrm{Zr}$ compounds as pre-catalysts will be in the focus of further studies.

\section{Acknowledgements}

This work was supported by the FWF SFB "FOXSI" project part F4503-N16. L. Mayr acknowledges financial support via a scholarship of the carinthian Confederation of Industry (Industriellenvereinigung Kärnten).

\section{References}

[1] E. Ivers-Tiffée, K.H. Härdtl, W. Menesklou, J. Riegel, Principles of solid state oxygen sensors for lean combustion gas control, Electrochim. Acta 47 (2001) 807-814.

[2] G.C. Kostogloudis, C. Ftikos, A. Ahmad-Khanlou, A. Naoumidis, D. Stöver, Chemical compatibility of alternative perovskite oxide SOFC cathodes with doped lanthanum gallate solid electrolyte, Solid State Ionics 134 (2000) 127-138.

[3] J.H. Lee, Review on zirconia air-fuel ratio sensors for automotive applications, J. Mater. Sci. 38 (2003) 4247-4257. 
[4] M. Copel, M. Gribelyuk, E. Gusev, Structure and stability of ultrathin zirconium oxide layers on Si(001), Appl. Phys. Lett. 76 (2000) 436-438.

[5] K.J. Hubbard, D.G. Schlom, Thermodynamic stability of binary oxides in contact with silicon, J. Mater. Res. 11 (1996) 2757-2776.

[6] T. Ngai, W.J. Qi, R. Sharma, J. Fretwell, X. Chen, J.C. Lee, S. Banerjee, Electrical properties of $\mathrm{ZrO}_{2}$ gate dielectric on SiGe, Appl. Phys. Lett. 76 (2000) 502-504.

[7] Y. Han, J. Zhu, Surface Science Studies on the Zirconia-Based Model Catalysts, Top. Catal. 56 (2013) 1525-1541.

[8] S. Yang, A. Maroto-Valiente, M. Benito-Gonzalez, I. Rodriguez-Ramos, A. GuerreroRuiz, Methane combustion over supported palladium catalysts: I. Reactivity and active phase, Appl.Catal., B 28 (2000) 223-233.

[9] J. Wambach, A. Baiker, A. Wokaun, $\mathrm{CO}_{2}$ hydrogenation over metal/zirconia catalysts, Phys. Chem. Chem. Phys. 1 (1999) 5071-5080.

[10] K.-i. Fujimoto, F.H. Ribeiro, M. Avalos-Borja, E. Iglesia, Structure and Reactivity of $\mathrm{PdO}_{\mathrm{x}} / \mathrm{ZrO}_{2}$ Catalysts for Methane Oxidation at Low Temperatures, J. Catal. 179 (1998) 431442.

[11] D. He, Y. Ding, H. Luo, C. Li, Effects of zirconia phase on the synthesis of higher alcohols over zirconia and modified zirconia, J. Mol. Catal. A: Chem. 208 (2004) 267-271.

[12] H. Purnama, F. Girgsdies, T. Ressler, J.H. Schattka, R.A. Caruso, R. Schomacker, R. Schlogl, Activity and selectivity of a nanostructured $\mathrm{CuO} / \mathrm{ZrO}_{2}$ catalyst in the steam reforming of methanol, Catal. Lett. 94 (2004) 61-68.

[13] A. Atkinson, S. Barnett, R.J. Gorte, J.T.S. Irvine, A.J. McEvoy, M. Mogensen, S.C. Singhal, J. Vohs, Advanced anodes for high-temperature fuel cells, Nat. Mater. 3 (2004) 1727. 
[14] X.D. Zhou, S.C. Singhal, FUEL CELLS - SOLID OXIDE FUEL CELLS Overview, in:

J. Editor-in-Chief: Garche (Ed.) Encyclopedia of Electrochemical Power Sources, Elsevier, Amsterdam, 2009, pp. 1-16.

[15] J. Maček, B. Novosel, M. Marinšek, Ni-YSZ SOFC anodes-Minimization of carbon deposition, J. Eur. Ceram. Soc. 27 (2007) 487-491.

[16] A. Fuerte, R.X. Valenzuela, L. Daza, Preparation and characterisation of SOFC anodic materials based on Ce-Cu, J. Power Sources 169 (2007) 47-52.

[17] A. Hornés, D. Gamarra, G. Munuera, J.C. Conesa, A. Martínez-Arias, Catalytic properties of monometallic copper and bimetallic copper-nickel systems combined with ceria and $\mathrm{Ce}-\mathrm{X}(\mathrm{X}=\mathrm{Gd}, \mathrm{Tb})$ mixed oxides applicable as SOFC anodes for direct oxidation of methane, J. Power Sources 169 (2007) 9-16.

[18] M.D. Gross, J.M. Vohs, R.J. Gorte, A study of thermal stability and methane tolerance of Cu-based SOFC anodes with electrodeposited Co, Electrochim. Acta 52 (2007) 1951-1957.

[19] A. Paulidou, R.M. Nix, Growth and characterisation of zirconia surfaces on $\mathrm{Cu}(111)$, Phys. Chem. Chem. Phys. 7 (2005) 1482-1489.

[20] L. Mayr, N. Köpfle, A. Auer, B. Klötzer, S. Penner, An (ultra) high-vacuum compatible sputter source for oxide thin film growth, Rev. Sci. Instrum. 84.9 (2013): 094103.

[21] A. Karim, T. Conant, A. Datye, The role of PdZn alloy formation and particle size on the selectivity for steam reforming of methanol, J. Catal. 243 (2006) 420-427.

[22] C. Rameshan, W. Stadlmayr, C. Weilach, S. Penner, H. Lorenz, M. Hävecker, R. Blume, T. Rocha, D. Teschner, A. Knop-Gericke, R. Schlögl, N. Memmel, D. Zemlyanov, G. Rupprechter, B. Klötzer, Subsurface-Controlled $\mathrm{CO}_{2}$ Selectivity of PdZn Near-Surface Alloys in $\mathrm{H}_{2}$ Generation by Methanol Steam Reforming, Angew. Chem. Int. Ed. 49 (2010) 32243227.

[23] C. Rameshan, C. Weilach, W. Stadlmayr, S. Penner, H. Lorenz, M. Hävecker, R. Blume, T. Rocha, D. Teschner, A. Knop-Gericke, R. Schlögl, D. Zemlyanov, N. Memmel, G. 
Rupprechter, B. Klötzer, Steam reforming of methanol on PdZn near-surface alloys on Pd(111) and Pd foil studied by in-situ XPS, LEIS and PM-IRAS, J. Catal. 276 (2010) 101113.

[24] C. Rameshan, W. Stadlmayr, S. Penner, H. Lorenz, N. Memmel, M. Hävecker, R. Blume, D. Teschner, T. Rocha, D. Zemlyanov, A. Knop-Gericke, R. Schlögl, B. Klötzer, Hydrogen Production by Methanol Steam Reforming on Copper Boosted by Zinc-Assisted Water Activation, Angew. Chem. 124 (2012) 3057-3061.

[25] V. Schott, H. Oberhofer, A. Birkner, M. Xu, Y. Wang, M. Muhler, K. Reuter, C. Wöll, Chemical Activity of Thin Oxide Layers: Strong Interactions with the Support Yield a New Thin-Film Phase of ZnO, Angew. Chem. Int. Ed. 52 (2013) 11925-11929.

[26] L. Mayr, R. Rameshan, B. Klötzer, S. Penner, C. Rameshan, Combined UHV/highpressure catalysis setup for depth-resolved near-surface spectroscopic characterization and catalytic testing of model catalysts, Rev. Sci. Instrum. 85.5 (2014) 055104.

[27] C.D. Wagner, W.M. Riggs, L.E. Davis, J.F. Moulder, G.E. Muilenberg, Handbook of XRay Photoelectron Spectroscopy, Perkin-Elmer Corporation, Physical Electronics Division, Eden Prairie, Minnesota, 1979.

[28] L. Mayr, H. Lorenz, M. Armbrüster, S.A. Villaseca, Y. Luo, R. Cardoso, U. Burkhardt, D. Zemlyanov, M. Haevecker, R. Blume, A. Knop-Gericke, B. Klötzer, S. Penner, The catalytic properties of thin film Pd-rich $\mathrm{GaPd}_{2}$ in methanol steam reforming, J. Catal. 309 (2014) 231-240.

[29] A.E. Hughes, B.A. Sexton, Comments on the use of implanted Ar as a binding energy reference, J. Electron Spectrosc. Relat. Phenom. 50 (1990) C15-C18.

[30] C.D. Wagner, D.A. Zatko, R.H. Raymond, Use of the oxygen KLL Auger lines in identification of surface chemical states by electron spectroscopy for chemical analysis, Anal. Chem. 52 (1980) 1445-1451.

[31] CasaXPS Version 2.3.16 Pre-rel 1.4, in, Casa Software Ltd, 2011. 
[32] D. Majumdar, D. Chatterjee, X-ray photoelectron spectroscopic studies on yttria, zirconia, and yttria-stabilized zirconia, J. Appl. Phys. 70 (1991) 988-992.

[33] C.J. Powell, A. Jablonski, NIST Electron Effective-Attenuation-Length Database SRD 82, National Instititue of Standards and Technology, Gaithersburg, 2011.

[34] J.J. Yeh, Atomic Calculation of Photoionization Cross-Sections and Asymmetry Parameters, Gordon and Breach Science Publishers, Langhorne, PE (USA), 1993.

[35] C.S. Fadley, Basic concepts of X-ray photoelectron spectroscopy, Electron Spectrosc. Theory, Tech. Appl. 2 (1978).

[36] N.C.M. Lawrence E. Davis, Paul W. Palmberg, Gerald E. Riach, Roland E. Weber, Handbook of Auger Electron Spectroscopy, Physical Electronics Division Perkin-Elmer Corporation, 1978.

[37] Y. Martynova, S. Shaikhutdinov, H.-J. Freund, CO Oxidation on Metal-Supported Ultrathin Oxide Films: What Makes Them Active?, ChemCatChem, 5 (2013) 2162-2166.

[38] P. Dilara, J. Vohs, Interaction of CO with Pt Supported on $\mathrm{ZrO}_{2}$ (100): Evidence for CO

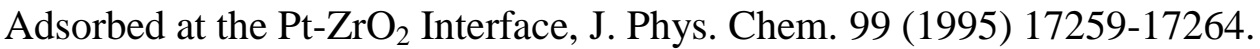

[39] T. Onishi, H. Abe, K.-i. Maruya, K. Domen, I.R. spectra of hydrogen adsorbed on $\mathrm{ZrO}_{2}$, J. Chem. Soc., Chem. Commun. (1985) 617-618.

[40] I. Ritzkopf, S. Vukojević, C. Weidenthaler, J.-D. Grunwaldt, F. Schüth, Decreased CO production in methanol steam reforming over $\mathrm{Cu} / \mathrm{ZrO}_{2}$ catalysts prepared by the microemulsion technique, Appl.Catal. A: General, 302 (2006) 215-223. 
